\title{
Effects of Strategic Choices for the Postmerger Manufacturer on Supply Chain Members
}

\author{
Huailiang Zhang $(\mathbb{D}$, Yan Zhou, and Minghui Jiang $(\mathbb{D}$ \\ School of Management, Harbin Institute of Technology, Harbin 150001, China \\ Correspondence should be addressed to Minghui Jiang; jiangminghui@hit.edu.cn
}

Received 7 July 2021; Revised 15 November 2021; Accepted 1 February 2022; Published 26 February 2022

Academic Editor: Florentino Borondo

Copyright (C) 2022 Huailiang Zhang et al. This is an open access article distributed under the Creative Commons Attribution License, which permits unrestricted use, distribution, and reproduction in any medium, provided the original work is properly cited.

\begin{abstract}
To investigate the impact of different strategies adopted by the merged firm on supply chain members, we consider a two-tier supply chain involving two suppliers and multiple manufacturers. Different from most studies, manufacturers, downstream in the supply chain, are asymmetric and produce differentiated products. Due to the differences between products, the postmerger manufacturer can choose focus strategy to generate synergy effect or differentiation strategy to implement price collusion. We give equilibrium results for the supply chain under different strategies. Theoretical analysis shows that for supplier, no matter which strategy is chosen, the price sensitivity for suppliers will increase. Surprisingly, the merger has the opposite effect on the profits of two suppliers under differentiation strategy. Regarding the strategic options after the merger, our research indicates that with the increased substitutability between products, shifting from differentiation strategy to focus strategy should be taken by the postmerger manufacturer. In addition, when focus strategy is chosen and the synergy effect is weak, or when differentiation strategy is chosen and the substitution between products is small, the merger may be beneficial to nonparticipating manufacturers.
\end{abstract}

\section{Introduction}

Mergers and acquisitions are the product of fierce competition between firms and an important strategy to enhance competitive advantage. Horizontal mergers occur between firms that are at the same level of the supply chain and produce homogeneous or substitute products. In this study, we mainly focus on horizontal mergers in downstream of the supply chain. In the process of satisfying consumer demand for products, many firms have formed specialized division of labour and cooperation, thus improving production efficiency and enhancing the ability to resist market fluctuations [1]. In the vertical dimension of the supply chain, upstream and downstream firms form a supply-demand relationship, and in the horizontal dimension, there are also many firms competing with each other in the intermediate product market or the final product market. The equilibrium result of supply chain is formed by the interaction between upstream and downstream firms and between firms at the same level.
Therefore, the horizontal merger between two firms will not only change the production decision, operation decision, and pricing decision of the participating firms but also affect other firms in the supply chain by changing the structure of the supply chain and the competitive relationship. So, this study investigates the effect of different strategies adopted by the merged firm on all firms in the supply chain.

In most research of the supply chain management, the upstream and downstream of the supply chain have the same market structure $[2,3]$. Undoubtedly, this assumption ignores the difference in production and competition between upstream and downstream firms. In many industries, the market structure is not the same at different levels of the supply chain, in which there are fewer upstream firms and more downstream firms. Similarly, Glock and Kim [4] considered a supply chain involving one vendor and multiple retailers. However, monopoly is generally not allowed by antitrust authorities. In the global IT market, there are two major competitors in upstream of the supply chain, one 
large and one small, for example, Intel and AMD in the field of computer processor chips; and IBM and Sun Microsystems (acquired by Oracle in 2010) in high-end systems and service; in mobile phone processor market, there are Qualcomm, Samsung, Apple, and Marvell, one large firm and three small firms. In the market of routers, there are Cisco and Juniper networks. In downstream of the computer industry, Apple (Apple Inc.), Lenovo, Asus, Dell, HewlettPackard, Samsung, and other companies compete by selling differentiated products. Not only to circumvent the scrutiny of antitrust laws but also to stimulate its own technological innovation, the leader in the market generally leaves a firm as its competitor. In this study, we consider this type of supply chain and assume that there are two upstream firms, one large and one small. To the best of our knowledge, this study is the first to consider the situation that suppliers compete in the Stackelberg fashion and manufacturers engage in the Bertrand competition.

To meet the diverse needs of consumers, manufacturers have developed a variety of products to achieve the purpose of market segmentation, thereby getting rid of the fierce competition between homogeneous products. Therefore, in recent years, product categories have increased rapidly in all walks of life. Relying on different competitive advantages and product positioning, firms produce various products to cater to different consumer groups. Different product functions and qualities lead to different production costs. Therefore, there are products of different price points in the market for consumers to choose. However, products are assumed to be homogeneous in many studies. To close such a gap, we build a supply chain equilibrium model in that firms are heterogeneous and final products are differential. There are studies on the strategic choice of mergers. For example, Wei et al. [5] explored the different integration strategies with two complementary supply chains, and there are also studies on the effect of vertical mergers or horizontal mergers $[6,7]$. However, they consider the situation that the market is monopoly, oligopoly, or firms at the same tier in the supply chain are homogeneous. Little studies involve the selection of competitive strategies after the merger. For that reason, we want to explore the choice of competitive strategy after the horizontal merger.

To analyse the impact of downstream horizontal mergers, we consider a two-tier supply chain as described above that there are two suppliers and multiple manufacturers, which is based on but different from the studies of Cho [3] and Zhu et al. [8]. We assume that two suppliers act as the Stackelberg leader and follower, respectively, competing in quantity. Manufacturers with various marginal costs compete on price in downstream of the supply chain. Based on the basic model, we further analyse the effect of focus strategy and differentiation strategy adopted by the postmerger manufacturer. In the research process of this study, we use theoretical analysis and numerical analysis to answer the following questions:

(i) How do manufacturers make price decisions when products are heterogeneous and marginal costs are diverse? (ii) How does the substitutability between final products affect prices, production quantities, and profits of firms in the supply chain?

(iii) What are the equilibrium outcomes in the supply chain when the merged firm chooses focus strategy and differentiation strategy?

(iv) What competitive strategy should the postmerger manufacturer choose after the horizontal merger? Focus strategy or differentiation strategy?

The rest of this study is organized as follows. In Section 2, we sort out the literature related to our study. In Section 3, we build the basic model of this study, obtain the equilibrium results, and derive some findings from the pre-merger model. In Section 4, we give the equilibrium result of the supply chain under focus strategy and differentiation strategy. In Section 5, we use numerical analysis to compare the equilibrium results and gain further insight into the choice of strategies. The conclusion and future research are presented in Section 6.

\section{Literature Review}

Mergers and acquisitions are a product of competition between firms to a certain extent, which can help firms gain a competitive advantage. With regard to the motivation for horizontal mergers, Cho [3] believed that the most important is the synergy effect and competition effect. Kumar [9] took Hindalco, an Indian aluminium producer, as an example to analyse its globalization strategy through mergers and acquisitions. Yang et al. [10] analysed the horizontal merger of firms in the closed-loop supply chain and believed that mergers can reduce the competition between firms in the supply chain. Esfahani [11] believed that the speed of market price adjustment determined determines the motivation for mergers. Through empirical research, Ibrahimi and Meghouar [12] found that the benefits of mergers come from sales synergy, cost synergies, and hybrid synergies. Assuming yield uncertainty, Xiao [13] suggested that even if there is no synergy effect, firms have the motivation to achieve diversification by mergers. There is no doubt that strategic adjustment and increased profits can be achieved through the horizontal merger. However, most of the previous studies examined the issue in the direction of mergers and less considered the issue of postmerger strategy choice, which is often the key to the success of a merger.

As far as the antitrust authorities are concerned, the most concerned about the merger is whether it will lead to an increase in market prices and a decrease in consumer welfare [14-16]. To circumvent the scrutiny of antitrust authorities, many firms claim that they can reduce production costs through mergers and acquisitions and benefit consumers by selling more products at lower prices. Suppose that firms produced differentiated products, Deneckere and Davidson [17] found that any scale of horizontal mergers is beneficial to nonparticipant firms, but the merger can lead to higher prices, resulting in a decline in consumer welfare. Farrell and Shapiro [18] investigated the effects of mergers on firms in 
the Cournot oligopolistic market and concluded that any merger without synergy effect can lead to an increase in consumer prices. Similarly, the research of Esfahani [11] showed that the decrease in the number of firms is harmful to consumers when there is no cost reduction. Zhu et al. [8] believed that an upstream horizontal merger is more detrimental to consumers when only the market power effect is considered. Horizontal mergers that occur upstream or downstream in the supply chain had the same effect on consumers with the same degree of synergy effect. Most of the above research ignores product differences in real life. Our research finds that pricing for manufacturers may show exact opposite variation under different strategies.

The subject of this study is also related to the research of the Bertrand competition and the Stackelberg competition in the supply chain. As for price competition and quantity competition, some scholars have launched a comparative analysis of the Cournot competition and the Bertrand competition from the perspectives of random yield, tacit collusion, and bargaining approach [19-21]. If the products are homogeneous, the firms with higher production costs would withdraw from the market in price competition. Therefore, most of the research on the Bertrand price competition is based on the assumption of differentiated products $[8,22,23]$. In this study, we need to set that the substitutability between products is below the threshold for any manufacturer to withdraw from the market. In the Stackelberg competition, one firm acts as the industry leader and is able to implement its decision before its rivals. Unlike the Cournot competition, the leader in the Stackelberg competition has the first-mover advantage. The research of Vardy [24] showed that if the followers can cobserve the leader's behaviour at a certain cost, the leader's commitment will not work. Heywood and McGinty [25] examined the consequences of the merger with a leader and a follower competing in the Stackelberg sense, which is beneficial to both sides. Cho [3] separately discussed the effect of horizontal mergers when manufacturers and retailers move first, respectively. Li and Chen [26] constructed a game-theoretic model to study the retailer's backward integration strategy when the retailer acts as a leader. Yang et al. [27] used the dynamic production game model to analyse the chaotic behaviours in the Stackelberg game. There are three game models in the supply chain we have studied. Upstream suppliers act as the Stackelberg leader to provide manufacturers with intermediate products, and the quantity competition and the price competition are carried out between suppliers and between manufacturers, respectively.

Cost leadership, differentiation strategy, and focus strategy are proposed by Michael Porter, which are used to help firms to achieve competitive advantage. Hit et al. [28] defined focus strategy as a marketing strategy that focusses on delivering a product or a service to a specific market segment. In our research, focus strategy means that the postmerger manufacturer focusses on a specific target market to produce a product, to meet consumer demand through price advantages. There is scant research on focus strategy. Laosirihongthong et al. [29] used Thailand survey data to analyse the effect of a broad market strategy and a niche market strategy on operation practices. To meet the diversified demands of consumers and the rapid changes in the market, AlGeddawy and ElMaraghy [30] proposed the concept of delayed product differentiation, which is to add product characteristic in the final stage of product production. Based on the product quality differences, Liu and Zhang [31] studied the dynamic price mechanism design for two firms providing differentiated products to consumers. Research showed that if customers are more strategic, the low-quality firm suffers more. Suppose there are two firms competing in a vertically differentiated market based on quality differences, Baron [32] researched the competitive game of corporate innovation. Mandal and Jain [33] analysed the effect of part outsourcing and quality differentiation on component quality decisions and yield decision through a stylized game-theoretic mode. In our research, the product differentiation is based on cost. In addition, Sousa and da Silveira [34] used structural equations to empirically analyse the relationship between market complexity and product and service differentiation strategies. Although the aforementioned studies have examined the choice of competitive strategies from different perspectives, few scholars have analysed how postmerger firms should choose focus strategy or differentiation strategy from a theoretical perspective. Therefore, the research in this study has important implications for the choice of postmerger strategies of firms.

\section{The Premerger Model and Analysis}

We consider a two-level supply chain model with different upstream and downstream market structures. In upstream of the supply chain, two asymmetric suppliers, facing the same demand function and competing in the Stackelberg sense, provide homogeneous intermediate products to manufacturers. We use the subscripts $l$ and $f$ to denote the leader and the follower, respectively. Manufacturers need to purchase parts from suppliers and sell them to retailers or consumers after production and processing. Similar to the research in supply chain management [35-37], we assume that the production of one final product requires one unit of raw material. Because of the substitution and difference between products, manufacturers are heterogeneous and compete with each other on price.

We first investigate the premerger equilibrium model of the supply chain. Followed the research of $[6,8,38]$, we suppose that the inverse demand function for each manufacturer is as follows:

$$
p_{i}=\alpha-q_{i}-\beta \sum_{j \neq i} q_{j}, \quad \text { for } i=1,2, \ldots n,
$$

where $\alpha$ represents the absolute size of the market and $\beta \in(0,1)$ represents the degree of substitutability of final products produced by manufacturers. With the increase in $\beta$, the difference between final products gradually decreases. The demand for each manufacturer is given as follows: 


$$
q_{i}=\frac{\alpha}{1+\beta(n-1)}-\frac{1+\beta(n-2)}{(1-\beta)[1+\beta(n-1)]} p_{i}+\frac{\beta}{(1-\beta)[1+\beta(n-1)]} \sum_{j \neq i} p_{j}
$$

This demand function is very suitable to portray the price competitive relationship between different products. When determining product prices, manufacturers must not only consider the decline in demand caused by high pricing but also consider the fall in marginal profit caused by low pricing. As product substitutability increases, price changes in other products have a greater impact on changes in demand for this product. Given the intermediate product price $w$ and based on the relationship between demand and price, the profit for each manufacturer can be represented as follows:

$$
\pi_{i}=\left(p_{i}-w-v_{i}\right) q_{i}
$$

where $v_{i}$ is the marginal production cost of manufacturer $i$. The production costs vary from manufacturer to manufacturer.

Proposition 1. Given the wholesale price by suppliers, the production cost, and the competitive relationship between manufacturers, the price set by manufacturer $i$ should be as follows: $p_{i}=(a+w) /(2-(n-1) b)+v_{i} /(b+2)+b \sum v_{j} /$ $((2-(n-1) b)(b+2))$, where $a=\alpha(1-\beta) /(1+\beta(n-2))$ and $b=\beta /(1+\beta(n-2))$.

$p_{i}$ is substituted into $q_{i}$ and $\pi_{i}$, and the production quantity and profit of manufacturer $i$ can be represented as follows:

$$
\begin{aligned}
& q_{i}=\left(p_{i}-w-v_{i}\right) \frac{1+\beta(n-2)}{(1-\beta)[1+\beta(n-1)]}, \\
& \pi_{i}=\left(p_{i}-w-v_{i}\right)^{2} \frac{1+\beta(n-2)}{(1-\beta)[1+\beta(n-1)]} .
\end{aligned}
$$

According to the relationship between demand and price, we can get the whole quantity produced by manufacturers as follows:

$$
Q=\frac{n \alpha}{(1+\beta(n-1))}+\frac{n(a+w)+\sum v_{j}}{(1+\beta(n-1))(2-(n-1) b)}
$$

The wholesale price charged by suppliers can be represented as follows:

$$
w=\alpha-\frac{\sum v_{j}}{n}-\frac{(1+\beta(n-1))(2+\beta(n-3))}{n(1+\beta(n-2))} Q
$$

where $\alpha-\sum v_{j} / n$ can be regarded as "market potential" and $(1+\beta(n-1))(2+\beta(n-3)) /(n(1+\beta(n-2)))$ can be regarded as "price sensitivity" for suppliers.

Different from the market structure in downstream of the supply chain, upstream suppliers have a sequence in their decision-making. The leader has the first-mover advantage and declares the quantity of production $q_{l}$ firstly. The follower observes this and decides on its production quantity $q_{f}$. To find the Nash equilibrium of the game between suppliers, we use backward induction. Starting with analysing the decision of the follower, the follower's profit can be represented as follows:

$$
\pi_{f}=\left(\alpha-\frac{\sum v_{j}}{n}-\frac{2+\beta(n-3)}{1+\beta(n-2)} \frac{1+\beta(n-1)}{n}\left(q_{f}+q_{l}\right)-v_{f}\right) q_{f}
$$

The first-order optimal condition $\partial \pi_{f} / \partial q_{f}=0$ gives the optimal response of the follower, and we can get the following:

$$
q_{f}=\frac{\left(\alpha n-\sum v_{j}-n v_{f}\right)(1+\beta(n-2))}{2(2+\beta(n-3))(1+\beta(n-1))}-\frac{q_{l}}{2} .
$$

So, the profit function of the leader is given as follows:

$$
\pi_{l}=\frac{1}{2}\left(\alpha-\frac{\sum v_{j}}{n}+v_{f}-2 v_{l}-\frac{2+\beta(n-3)}{1+\beta(n-2)} \frac{1+\beta(n-1)}{n} q_{l}\right) q_{l} .
$$


Solving the equation $\partial \pi_{l} / \partial q_{l}=0$, we can have the following:

$$
q_{l}=\frac{n(1+\beta(n-2))}{2(2+\beta(n-3))(1+\beta(n-1))}\left(\alpha-\frac{\sum v_{j}}{n}+v_{f}-2 v_{l}\right) .
$$

Substituting the expression for $q_{l}$ into the follower's response function, we can obtain the following:

$$
q_{f}=\frac{n(1+\beta(n-2))}{4(2+\beta(n-3))(1+\beta(n-1))}\left(\alpha-\frac{\sum v_{j}}{n}-3 v_{f}+2 v_{l}\right)
$$

Substituting this value into the function of the total production and wholesale price, we can get the following:

$$
\begin{aligned}
& Q=\frac{n(1+\beta(n-2))}{4(2+\beta(n-3))(1+\beta(n-1))}\left(3 \alpha-3 \frac{\sum v_{j}}{n}-v_{f}-2 v_{l}\right), \\
& w=\frac{1}{4}\left(\alpha-\frac{\sum v_{j}}{n}+v_{f}+2 v_{l}\right) .
\end{aligned}
$$

The profit functions of suppliers can be represented as follows:

$$
\begin{aligned}
& \pi_{f}=\frac{n(1+\beta(n-2))}{16(2+\beta(n-3))(1+\beta(n-1))}\left(\alpha-\frac{\sum v_{j}}{n}-3 v_{f}+2 v_{l}\right)^{2}, \\
& \pi_{l}=\frac{n(1+\beta(n-2))}{8(2+\beta(n-3))(1+\beta(n-1))}\left(\alpha-\frac{\sum v_{j}}{n}+v_{f}-2 v_{l}\right)^{2} .
\end{aligned}
$$

Substituting $w$ into $p_{i}, q_{i}$, and $\pi_{i}$, equilibrium results for manufacturers can be obtained.

There are three game modes in our basic model. In the horizontal dimension, downstream manufacturers engage in the Bertrand price competition, while upstream suppliers engage in the Stackelberg competition. In the vertical dimension, suppliers act as the Stackelberg leader and manufacturers act as the follower, in which suppliers make price and production decisions after knowing the demand functions of manufacturers. Because downstream firms compete in price, some manufacturers who have higher production costs than others would drop out of the market when final products are homogeneous. So, we need to set that the value of $\beta$ is lower than that making any manufacturers to withdraw from the market.

From the equilibrium result, we can come to some interesting findings. Firstly, in downstream of the supply chain, due to the substitution relationship between products, it is a mutually impact relationship between production costs and prices. It is obvious that the manufacturer's cost has a significantly greater effect on its price than other firms. However, increased costs for all manufacturers would have a positive effect on $p_{i}$. Since manufacturers have different production costs, each manufacturer is also diverse in pricing and production quantity, which is extremely different from the Cournot quantity competition. Secondly, equilibrium results in upstream of the supply chain make us surprised that the substitutability between final products has no effect on the wholesale price, which can be derived from the function of wholesale price. However, according to suppliers' profit functions, we can find that although the substitutability of final products does affect the marginal profit of suppliers, the profits of suppliers would decrease with $\beta$, which is consistent with the change in production. In addition, due to the different decision-making sequences, the effect of the leader's marginal cost in wholesale price is significant than that of the follower.

Before proceeding with further analysis, we discuss the effect of the degree of substitutability of final products on the equilibrium of the supply chain. $\beta$ has a negative effect on $p_{i}, \pi_{i}$, production quantities, and profits of upstream firms. In other words, the increase in the difference between the final products is conducive to the profit growth of all firms in the supply chain. For consumers, diverse consumer needs will be met with a loss of consumer welfare. For manufacturers, with increased substitutability between products, the production quantities of low-cost manufacturers increase significantly, while the production quantities of high-cost manufacturers decline rapidly due to their cost disadvantages in the market competition.

\section{The Choice of Strategies by the Postmerger Manufacturer}

In this section, we will derive equilibrium results under different strategies of the postmerger manufacturer and analyse the impact on other firms in the supply chain. Since final products are heterogeneous, the merged firm can choose focus strategy or differentiation strategy. When focus strategy is chosen, the postmerger manufacturer would only retain and produce one product. In this case, the purpose of choosing horizontal merger is to reduce production cost, increase market share, and increase profit through technology sharing or economies of scale. When differentiation strategy is chosen, it would choose to continue to produce two products after the merger. At this point, the postmerger manufacturer can conduct price collusion to maximize the overall profit. To focus on the effect of the horizontal merger, the cost of the merger is assumed to be zero. To distinguish equilibrium results before and after the merger and equilibrium results under different strategies, we use superscripts $F$ and $D$ to denote choosing focus strategy and differentiation strategy separately. When analysing the effect of the horizontal merger, we assume that manufacturers 1 and 2 merge into the merged firm and the horizontal merger does not affect the substitutability between products. We use subscript $m$ to denote the postmerger manufacturer. 
4.1. Equilibrium Results under Focus Strategy. This subsection shows equilibrium results in the supply chain when the postmerger manufacturer chooses focus strategy. The research of $[3,8,39,40]$ has elaborated on the synergy effect caused by mergers. Therefore, we would not go into details about the source of synergy effect. The marginal cost reduction caused by synergy effect can increase the merged firm's marginal profit and market share. However, merging to produce only one product will result in the loss of market share for the other product. This means that the merged firm needs to weigh whether the increase in profit by lower cost can compensate for the decline in profit caused by the loss of market share.

After the horizontal merger, assume that the cost of the postmerger manufacturer is $v_{m}$ and $v_{m}<\left(v_{1}+v_{2}\right) / 2$. For manufacturers, the problem with profit maximization becomes the following:

$$
\left\{\begin{array}{l}
\pi_{m}^{F}=\left(p_{m}^{F}-w^{F}-v_{m}\right) q_{m}^{F}, \\
\pi_{i}^{F}=\left(p_{i}^{F}-w^{F}-v_{i}\right) q_{i}^{F}, \quad \text { for } i=3 \ldots n,
\end{array}\right.
$$

where

$$
\begin{aligned}
& q_{m}^{F}=\frac{\alpha}{1+\beta(n-1)}-\frac{1+\beta(n-2)}{(1-\beta)[1+\beta(n-1)]} p_{m}^{F}+\frac{\beta}{(1-\beta)[1+\beta(n-1)]} \sum_{j=3} p_{j}^{F}, \\
& q_{i}^{F}=\frac{\alpha}{1+\beta(n-1)}-\frac{1+\beta(n-2)}{(1-\beta)[1+\beta(n-1)]} p_{i}^{F}+\frac{\beta}{(1-\beta)[1+\beta(n-1)]}\left(\sum_{j=3 \& j \neq i} p_{j}^{F}+p_{m}^{F}\right) .
\end{aligned}
$$

Following the analysis steps in $\$ 3$, prices for manufacturers after the merger should be set as follows:

$$
\left\{\begin{array}{l}
p_{m}^{F}=\frac{w^{F}(\beta(n-3)+1)+\alpha(1-\beta)}{2+\beta(n-4)}+\frac{1+\beta(n-3)}{2+\beta(2 n-5)}, \\
v_{m}+\frac{\beta(\beta(n-3)+1)}{(2+\beta(n-4))(2+\beta(2 n-5))}\left(v_{m}+\sum_{j=3} v_{j}\right) \\
p_{i}^{F}=\frac{w^{F}(\beta(n-3)+1)+\alpha(1-\beta)}{2+\beta(n-4)}+\frac{1+\beta(n-3)}{2+\beta(2 n-5)}, \\
v_{i}+\frac{\beta(\beta(n-3)+1)}{(2+\beta(n-4))(2+\beta(2 n-5))}\left(v_{m}+\sum_{j=3} v_{j}\right) .
\end{array}\right.
$$

Proposition 2. For suppliers, when the postmerger manufacturer chooses focus strategy, the market potential and price sensitivity increase. The wholesale price faced by manufacturers increases.

The wholesale price is as follows:

$$
w^{F}=\frac{1}{4}\left(\alpha-\frac{\left(v_{m}+\sum_{j=3} v_{j}\right)}{(n-1)}+v_{f}+2 v_{l}\right) \text {. }
$$

The total production in the supply chain becomes the following:

$$
Q^{F}=\frac{(1+\beta(n-3))(n-1)}{4(2+\beta(n-4))(1+\beta(n-2))}\left(\frac{3 \alpha-3\left(v_{m}+\sum_{j=3}^{n} v_{j}\right)}{(n-1)}-v_{f}-2 v_{l}\right)
$$

Compared with the total production in the premerger scenario, in the right of $Q^{F}$, the first part decreases, while the second part increases. So, the total production may decrease or increase, which depends on the change in suppliers' price sensitivity and the degree of cost reduction in the merged firm. When the synergy effect is relatively weak, production quantities and profits for suppliers could be lower than before the merger. With the increase in synergy effect and the decrease in production cost, this situation will be reversed. It should be noted that this reversal occurs first in terms of profits and second in terms of production quantities as the synergy effect increases.
We next analyse the impact of the focus strategy on downstream firms in the supply chain. Due to the decline in average cost of downstream firms, the market potential for upstream firms increases, which eventually leads to an increase in the input price for the downstream firms. Because the postmerger manufacturer focusses on the production of one product, the market share and the profit acquired by another product would disappear after the merger. However, a sharp drop in cost can increase the market share and marginal profit. Under other conditions unchanged, the stronger the production substitution, the greater the increase 
in the postmerger manufacturer's market share and profit. For manufacturers that do not participate in the merger, the impact of focus strategy adopted by the postmerger manufacturer cuts both ways. On the one hand, the reduction in production categories reduces the degree of price competition between products, which can increase the market share of nonparticipating manufacturers. On the other hand, due to the decline in the average cost in downstream and the increase in input price, manufacturers need to face more intense price competition, which may lead to a decline in marginal profit and market share. This impact is particularly serious when the number of downstream firms is small.

\subsection{Equilibrium Results under Differentiation Strategy.}

When choosing differentiation strategy, the postmerger manufacturer still produces two kinds of products and maximizes profit through price collusion. Currently, the relationship between price and demand for each product remains as before the merger. When the postmerger manufacturer chooses differentiation strategy, the profit problem for downstream firms becomes the following:

$$
\left\{\begin{array}{l}
\pi_{m}^{D}=\left(p_{1}^{D}-w^{D}-v_{1}\right) q_{1}^{D}+\left(p_{2}^{D}-w^{D}-v_{2}\right) q_{2}^{D} \\
\pi_{i}^{D}=\left(P_{i}^{D}-w^{D}-v_{i}\right) q_{i}^{D}, \quad \text { for } i=3, \ldots, n
\end{array}\right.
$$

Proposition 3. When the postmerger manufacturer chooses differentiation strategy, the equilibrium prices for downstream manufacturers are as follows:

$$
\begin{aligned}
& p_{1}^{D}=\frac{\left(-2(n-3) w^{D}-(n-2)\left(v_{1}+v_{2}\right)\right) b^{2}+2\left(w^{D}-a-\sum_{j=3} v_{j}\right) b-4\left(a+w^{D}\right)}{4\left(b^{2}+(n-1) b-2\right)}+\frac{v_{1}}{2}, \\
& p_{2}^{D}=\frac{\left(-2(n-3) w^{D}-(n-2)\left(v_{1}+v_{2}\right)\right) b^{2}+2\left(w^{D}-a-\sum_{j=3} v_{j}\right) b-4\left(a+w^{D}\right)}{4\left(b^{2}+(n-1) b-2\right)}+\frac{v_{2}}{2}, \\
& p_{i}^{D}=\frac{\left(2 w^{D}+v_{1}+v_{2}\right) b^{3}+\left(4 w^{D}+v_{1}+v_{2}\right) b^{2}+2\left(-a-w^{D}-\sum v_{j}\right) b-4\left(a+w^{D}\right)}{2(b+2)\left(b^{2}+(n-1) b-2\right)}+\frac{v_{i}}{(b+2)} .
\end{aligned}
$$

On the right-hand side of the price expressions for two types of products in the postmerger manufacturer, the first part is the same, and the second part is about its own production cost. It can be found that an increase in cost does not lead to an equal increase in the price of the product.
Ignoring the differences between costs, the two types of products are consistent in terms of price setting.

At this time, the reverse demand function faced by upstream firms is as follows:

$$
w^{D}=\alpha-\frac{2 \sum v_{j}-\left(v_{1}+v_{2}\right)\left(b^{2}+b\right)}{2\left(n-b^{2}-b\right)}-\frac{(1+\beta(n-1))\left(2-b^{2}-(n-1) b\right)}{\left(n-b^{2}-b\right)} Q^{D} .
$$

Proposition 4. When $n>2 \sum v_{j} /\left(v_{1}+v_{2}\right)$, market potential decreases; when $n<2 \sum v_{j} /\left(v_{1}+v_{2}\right)$, market potential increases. The change in wholesale price is consistent with that in market potential. When differentiation strategy is chosen, the price sensitivity for suppliers increases after the merger.
When the postmerger manufacturer chooses differentiation strategy, the cost relationship between manufacturers determines the change in suppliers' market potential and wholesale price after the merge. The same as choosing focus strategy is that suppliers' price sensitivity would rise.

Through calculation, we can get that the total output in the supply chain is as follows:

$$
Q^{D}=\frac{\left(n-b^{2}-b\right)\left(3 \alpha+3\left(v_{1}+v_{2}\right)\left(b^{2}+b\right) / 2\left(n-b^{2}-b\right)-3 \sum v_{j} /\left(n-b^{2}-b\right)-v_{f}-2 v_{l}\right)}{4(1+\beta(n-1))\left(2-b^{2}-(n-1) b\right)}
$$

The input price for manufacturers is as follows:

$$
w^{D}=\frac{1}{4}\left(\alpha+\frac{\left(v_{1}+v_{2}\right)\left(b^{2}+b\right)}{2\left(n-b^{2}-b\right)}-\frac{\sum v_{j}}{\left(n-b^{2}-b\right)}+v_{f}+2 v_{l}\right)
$$


The wholesale price $w^{D}$ is substituted into $p_{1}^{D}, p_{2}^{D}$, and $p_{i}^{D}$, and substituting price expressions into production quantity functions, we can get the equilibrium results in downstream of the supply chain under differentiation strategy. Unlike adopting focus strategy, differentiation strategy adopted by the merged firm does not change the price and demand relationship between products. However, due to price collusion carried out by the postmerger manufacturer, manufacturers' price decisions also change accordingly; that is, the mode of competition between manufacturers changes.

\section{Numerical Analysis}

Due to the complicated form of the equilibrium results after the horizontal merger under different strategies, we compare the results by numerical analysis and infer more management applications based on the theoretical analysis. In $\$ 4$, we have analysed the changes in wholesale prices and total output after the merger, and these results are no longer displayed in numerical analysis. To analyse the changes in the equilibrium results before and after the merger, we set parameters as follows:

$$
\begin{aligned}
\alpha & =15, \\
n & =5, \\
v_{l} & =1.8, \\
v_{f} & =2 .
\end{aligned}
$$

In the theoretic analysis, we assume that costs vary among downstream manufacturers. In terms of the manufacturers' cost setting, we randomly generate five random numbers between 1 and 2 as marginal costs of downstream firms. The marginal costs of five manufacturers are, respectively, as follows:

$$
\begin{aligned}
& v_{1}=1.9, \\
& v_{2}=1.7, \\
& v_{3}=1.4, \\
& v_{4}=1.8, \\
& v_{5}=1.3 .
\end{aligned}
$$

Because of the similarity in the expressions of manufacturers that do not participate in the merger, we will take manufacturer 3 as an example to illustrate the equilibrium results for nonparticipating manufacturers, and the results of manufacturers 4 and 5 will no longer show.

\subsection{Comparison of Results under the Basic Model and the} Focus Strategy. When analysing the equilibrium results under focus strategy, we use $\Delta v=\left(v_{1}+v_{2}\right) / 2-v_{m}$ to denote the change in cost for the merged manufacturer. The synergy effect generated by horizontal merger increases with $\Delta v$. When showing the effect of focus strategy, we set $\beta=0.7$ and equilibrium results are shown in Figure 1.

In Figure 1, we, respectively, show the effect of the synergy effect on manufacturers' prices, production quantities, profits, and suppliers' profits under focus strategy. We can derive from Figure 1 that if there is no synergy effect, the prices of manufacturers after the merger would be higher than before the merger and consumer welfare will be reduced by higher prices.

With the increase in $\Delta v$, the prices of downstream manufacturers begin to fall, and the price decline of postmerger manufacturer is significantly greater than that of manufacturer 3, which is consistent with the cross-relationship between optimal prices and costs of manufacturers in the theoretical analysis. The sharp fall in price was accompanied by a dramatic increase in production and profits for the postmerger manufacturer. Although the synergy effect results in lower price for the merged firm, the cost advantage gives it an edge over other competitors, ultimately leading to a significant increase in market share and profit. $\Delta v$ has negative effect on production quantities and profits of nonparticipating manufacturers. The profits of upstream suppliers have the same trend as the synergy effect changes. With the enhancement of the synergy effect, the profits of upstream suppliers gradually change from being lower than before the merger to being higher than before the merger.

5.2. Comparison of Results under the Basic Model and the Differentiation Strategy. Next, we analyse the effect of the differentiation strategy on supply chain members. When products produced by manufacturers are highly substitutable and almost homogeneous, fierce price competition can cause higher-cost manufacturers to withdraw from the market. Because the raw materials used by manufacturers to produce final products are the same, the final products are unlikely to be completely different. Therefore, when analysing the differentiation strategy, we set $\beta \in[0.2,0.8]$. Since the adoption of differentiation strategy after the merger results in small changes in prices, production quantities, and profits, we show the results of the comparison before and after the merger in Figure 2.

From the comparison of the equilibrium results, the postmerger manufacturer's prices for both types of products are higher than before the merger; i.e., the postmerger manufacturer will raise prices to maximize profits by price collusion. The increase in the price could lead to a decrease in consumer demand for products 1 and 2. However, the substitution relationship between products has little impact on this change in demand. The marginal cost of product 1 is higher, and the postmerger price growth is also higher than that of product 2 . The decline in market demand for product 1 and product 2 is the opposite. With the increase in $\beta$, the increase in prices for products 1 and 2 shows a trend of first increasing and then decreasing, while the decrease in prices for manufacturers 3 continues to grow. The differentiation strategy can cause prices of nonparticipating manufacturers to fall, but their production quantities increase significantly as $\beta$ increases.

The impact of adopting the differentiation strategy on profits varies for firms in the supply chain. The postmerger manufacturer can benefit from the strategy, but the profit growth after the merger shows a trend of first growth and 


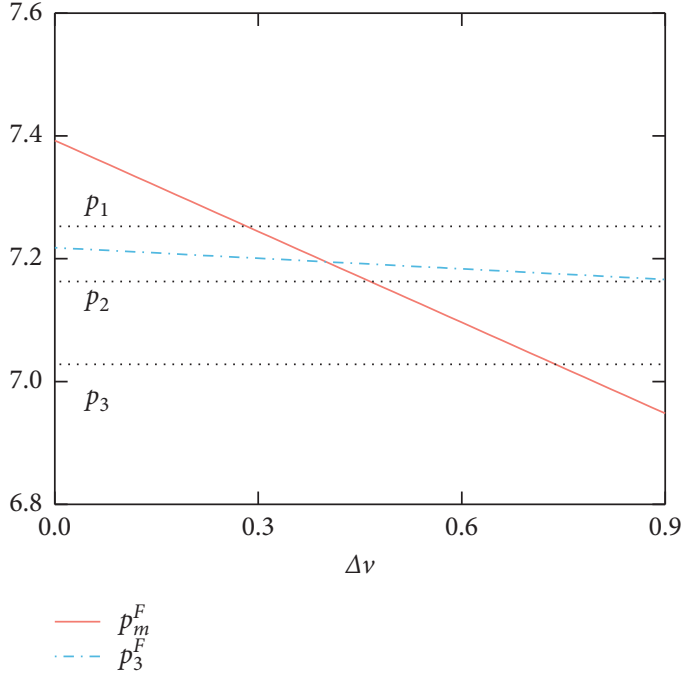

(a)

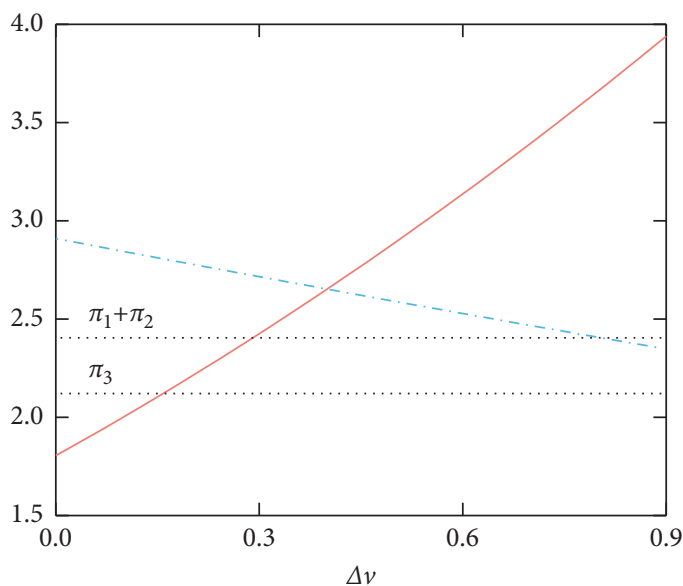

$-\pi_{m}^{F}$

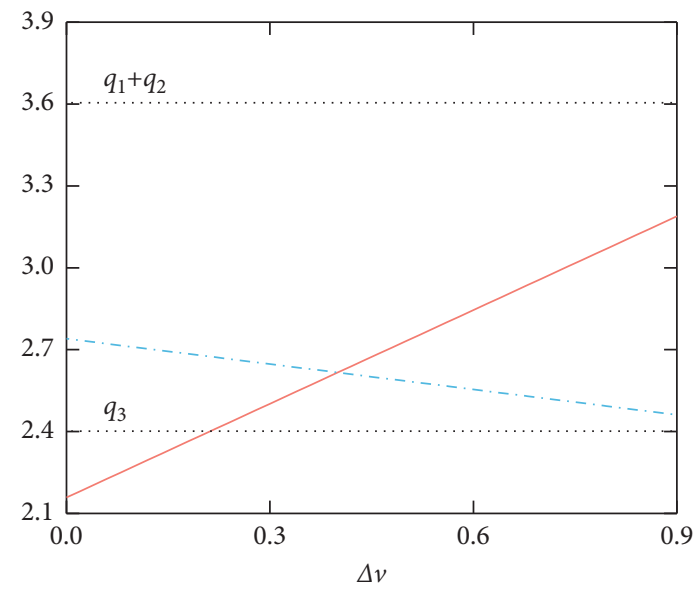

$-q_{m}^{F}$

(b)

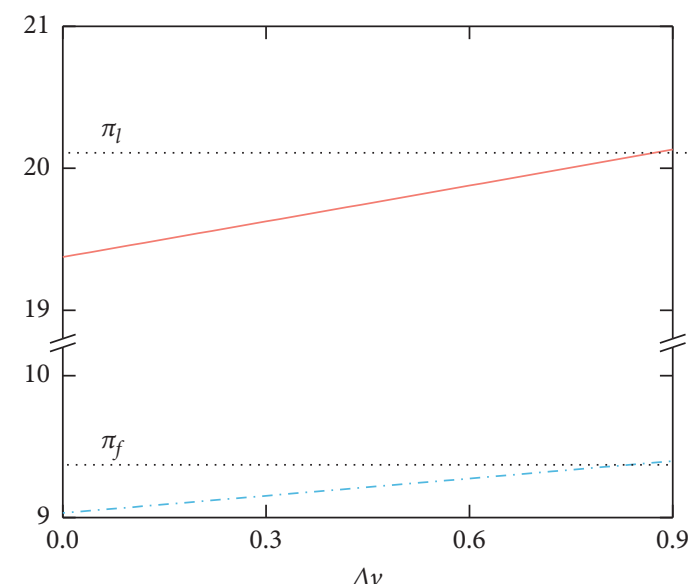

$-\begin{aligned}- & \pi_{l}^{F} \\ - & \pi_{f}^{F}\end{aligned}$

(c)

(d)

FIgURE 1: Effect of $\Delta v$ on equilibrium results of supply chain when $\beta=0.7$.

then decline with the increase in product substitution. When final products are less substitutable, the profit growth of manufacturer 3 is greater than that of the postmerger manufacturer. However, with the increase in $\beta$, the increase in manufacturer 3's profit changes from small to large and then rapidly declines and eventually becomes negative. Different from the research of $[2,3]$, upstream suppliers are heterogeneous in our research. When focus strategy is chosen, changes in profits of suppliers with the increase in synergy effect are the same. However, the differentiation strategy has an opposite effect on profits of the two upstream suppliers. When the postmerger manufacturer chooses the differentiation strategy, the leader's profit increases, while the follower's profit decreases.

5.3. Discussion on the Choice of Strategy. Although we have discussed the equilibrium results under different strategies, it is still unclear whether firms should merge horizontally and what strategy should be adopted after the merger. In this section, we further discuss whether the horizontal merger should be implemented and the choice of postmerger strategies. To investigate the effect of $\beta$ and $\Delta v$ on the choice of strategies, we need to compare the sum of the profit of manufacturers 1 and 2 with the profit of the postmerger manufacturer under different strategies. The results are shown in Table 1.

To compare the two strategies, we give the value of $\Delta v$ when $\pi_{m}^{F}=\pi_{1}+\pi_{2}$ and when $\pi_{m}^{F}=\pi_{m}^{D}$. Through these data, we can further understand the factors that affect the choice of strategies for the postmerger manufacturer. From Table 1, we can obtain that regardless of the value of $\beta$, the profit of the postmerger manufacturer is always higher than before the merger, even though the increase in profits was not significant. So, when $\pi_{m}^{F}=\pi_{1}+\pi_{2}, \Delta v$ is lower than that when $\pi_{m}^{F}=\pi_{m}^{D}$. With the increase in $\beta, \Delta v$, which 

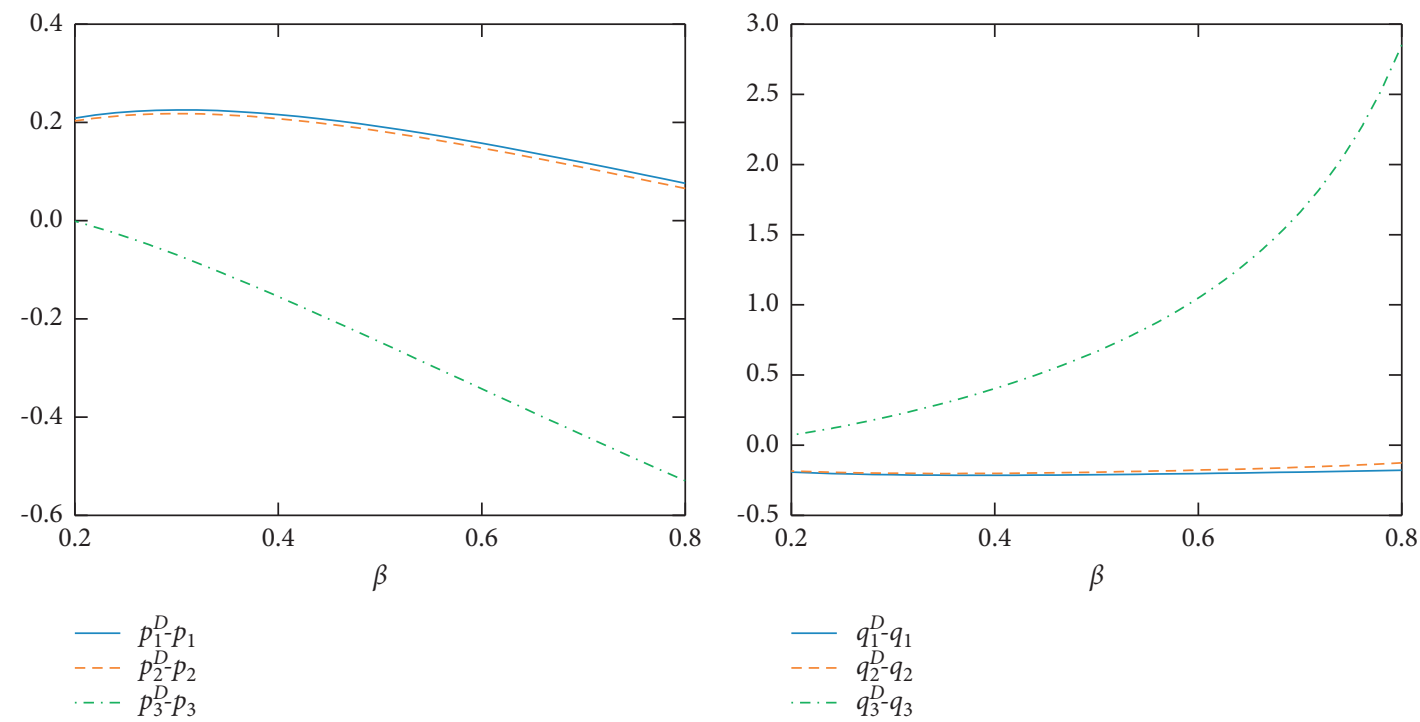

(a)
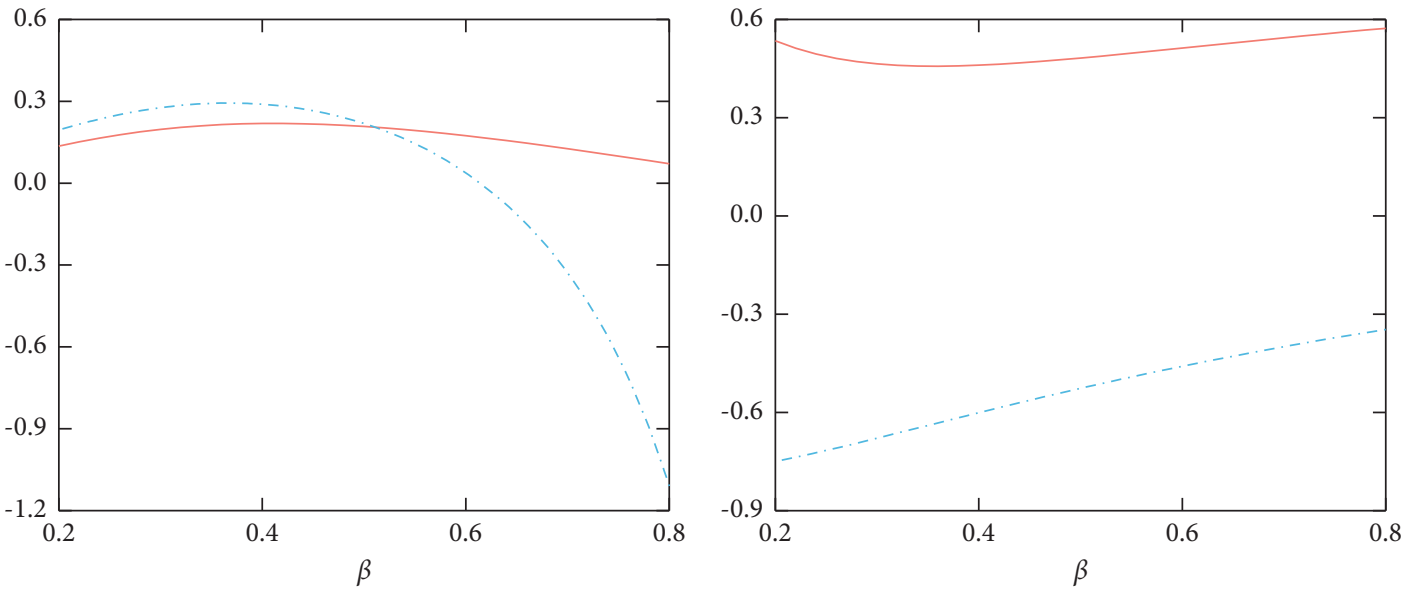

$\begin{array}{ll}- & \pi_{m}^{D}-\pi_{1}-\pi_{2} \\ -- & \pi_{3}^{D}-\pi_{3}\end{array}$

$\begin{array}{ll}- & \pi_{l}^{D}-\pi_{l} \\ -.- & \pi_{f}^{D}-\pi_{f}\end{array}$

(c)

(d)

FIgURE 2: Comparison of the equilibrium results before and after the merger with $\beta$.

TABLE 1: Comparison of the profit of the postmerger manufacturer under different strategies.

\begin{tabular}{lcccc}
\hline$\beta$ & $\pi_{1}+\pi_{2}$ & $\pi_{m}^{D}$ & $\Delta v$ when $\pi_{m}^{F}=\pi_{1}+\pi_{2}$ & $\Delta v$ when $\pi_{m}^{F}=\pi_{m}^{D}$ \\
\hline 0.2 & 17.218 & 17.362 & $*$ & $*$ \\
0.3 & 12.258 & 12.462 & $*$ & $*$ \\
0.4 & 8.674 & 8.898 & $*$ & 0.798 \\
0.5 & 6.004 & 6.216 & 0.723 & 0.548 \\
0.6 & 3.972 & 4.150 & 0.478 & 0.291 \\
0.7 & 2.406 & 0.535 & 0.154 & 0.192 \\
0.8 & 1.195 & 1.269 &
\end{tabular}

Note. We set $\Delta v \in[0,0.8]$ and ${ }^{*}$ represents that $\Delta v$ does not exist.

corresponds to $\pi_{m}^{F}=\pi_{m}^{D}$, will decrease. This means that for the same degree of synergy effect, the greater the substitutability between products, the more profitable for the postmerger manufacturer to adopt focus strategy.
Although it is always profitable for the postmerger manufacturer to adopt differentiation strategy, we do not consider the cost of implementing the horizontal merger. Therefore, it is necessary to compare the benefit and cost 
when firms intend to implement horizontal merger. In addition, if the postmerger manufacturer is prepared to choose focus strategy, it is more appropriate when the difference between products is small and the synergy effect is strong. In conclusion, when products are highly substitutable, focus strategy should be chosen, and when the substitutability between products is very low, differentiation strategy is more suitable.

\section{Conclusion}

In this study, we explore the effect of the horizontal merger on the supply chain under different strategies by combining theoretical analysis and numerical analysis. We construct a two-tier supply chain model with different upstream and downstream market structures. By assuming that downstream manufacturers are heterogeneous, we can further analyse the equilibrium outcomes of price competition between firms and explore the impact of firm costs and industry costs on their prices and profits. Due to the differences between final products, focus strategy and differentiation strategy are discussed as alternative strategies for the merged firm. Although the merged firm can always profit from differentiation strategy by implementing price collusion, this is not always the optimal choice for it. When synergy effect is strong and the differences between products are small, the merged firm should change from a differentiation strategy to focus strategy. For manufacturers, horizontal mergers of other firms at the same tier are not always detrimental. When substitutability between products is weak, horizontal mergers can reduce the level of competition between firms, thereby increasing the sales and profits of nonparticipating firms. When, on the other hand, there is a high degree of substitutability between products and synergy effect created by the merger is strong, the nonparticipating firms should take new actions to respond to changes in the market. Under the equilibrium state of supply chain, upstream firms are not immune to the ripple effects of the downstream horizontal merger. The impacts of the merger on upstream heterogeneous firms in supply chain are not always consistent, especially when differentiation strategy is adopted.

The research can be extended in the following aspects. In this study, we attribute the variability between products to difference in production costs, but in real life, the product differences may be due to quality, product functions, and other reasons. Therefore, it may be more realistic to set costs as a function of quality and include product quality in the consumer demand function. In addition, due to assumptions of the basic model, we only consider the differentiation strategy and focus strategy. Subsequent research can incorporate collaborative research and development behaviour between firms, and disequilibrium issues into supply chain research, considering firms' innovation strategy and supply chain coordination. Also, we only consider a two-tier supply chain composed of suppliers and manufacturers. In a supply chain with manufacturers and retailers, or in a multilevel supply chain, strategic choices and effects of horizontal mergers may also vary depending on market structure and firm behaviour. Future research could be further developed in these areas.

\section{Data Availability}

The data used to support the findings of this study are available from the corresponding author upon request.

\section{Conflicts of Interest}

The authors declare that there are no conflicts of interest regarding the publication of this study.

\section{Supplementary Materials}

(1) The proof of Proposition 1 gives how to get optimal prices for manufacturers. (2) The proof of Proposition 2 discusses how the focus strategy affects suppliers. (3) The proof of Proposition 3 gives the price decision process when the postmerger manufacturer chooses differentiation strategy. (4) The proof of Proposition 4 discusses how the differentiation strategy affects suppliers. (Supplementary Materials)

\section{References}

[1] P. Majumder and A. Srinivasan, "Leadership and competition in network supply chains," Management Science, vol. 54, no. 6, pp. 1189-1204, 2008.

[2] C. J. Corbett and U. S. Karmarkar, "Competition and structure in serial supply chains with deterministic demand," Management Science, vol. 47, no. 7, pp. 966-978, 2001.

[3] S.-H. Cho, "Horizontal mergers in multitier decentralized supply chains," Management Science, vol. 60, no. 2, pp. 356-379, 2014.

[4] C. H. Glock and T. Kim, "The effect of forward integration on a single-vendor-multi-retailer supply chain under retailer competition," International Journal of Production Economics, vol. 164, pp. 179-192, 2015.

[5] J. Wei, J. Zhao, and X. Hou, "Integration strategies of two supply chains with complementary products," International Journal of Production Research, vol. 57, no. 7, pp. 1972-1989, 2019.

[6] E. J. Anderson and Y. Bao, "Price competition with integrated and decentralized supply chains," European Journal of Operational Research, vol. 200, no. 1, pp. 227-234, 2010.

[7] C. L. Shi, W. Geng, and J. B. Sheu, "Integrating dual-channel closed-loop supply chains: forward, reverse or neither?" Journal of the Operational Research Society, vol. 72, 2020.

[8] J. Zhu, T. Boyaci, and S. Ray, "Effects of upstream and downstream mergers on supply chain profitability," European Journal of Operational Research, vol. 249, no. 1, pp. 131-143, 2016.

[9] N. Kumar, "How emerging giants are rewriting the rules of M\&A," Harvard Business Review, vol. 87, no. 5, pp. 115-121, 2009.

[10] Y. X. Yang, L. Niu, Z. Q. Huang, and G. G. Zhou, “Closedloop supply chain network redesigning model post the horizontal merger based on environmental responsibility," International Journal of Services Technology and Management, vol. 22, no. 3-5, pp. 179-202, 2016.

[11] H. Esfahani, "Profitability of horizontal mergers in the presence of price stickiness," European Journal of Operational Research, vol. 279, no. 3, pp. 941-950, 2019. 
[12] M. Ibrahimi and H. Meghouar, "Sources of value creation and destruction in horizontal mergers and acquisitions," Managerial Finance, vol. 45, no. 10/11, pp. 1398-1415, 2019.

[13] Y. Xiao, "Horizontal mergers under yield uncertainty," Production and Operations Management, vol. 29, no. 1, pp. 24-34, 2020.

[14] X. Gonzalez and M. J. Moral, "Effects of antitrust prosecution on retail fuel prices," International Journal of Industrial Organization, vol. 67, 2019.

[15] F. Malone and J. G. Sidak, "Should antitrust consent decrees regulate post-merger pricing?" Journal of Competition Law and Economics, vol. 3, no. 3, pp. 471-490, 2007.

[16] R. Bajo-Buenestado and D. Cahan, "Unification of oligopolistic markets for a homogeneous good in the presence of an antitrust commission," Journal of Industry, Competition and Trade, vol. 15, no. 3, pp. 239-256, 2015.

[17] R. Deneckere and C. Davidson, "Incentives to form coalitions with Bertrand competition," The RAND Journal of Economics, vol. 16 , no. 4, pp. 473-486, 1985.

[18] J. Farrell and C. Shapiro, "Horizontal mergers: an equilibrium analysis," The American Economic Review, vol. 80, no. 1, pp. 107-126, 1990.

[19] X. Yan, Y. Wang, and Z. Hong, "Comparison of Bertrand and Cournot competitions under random yield," International Journal of Production Research, vol. 54, no. 11, pp. 3256-3276, 2016.

[20] J. Bian, K. K. Lai, Z. Hua, X. Zhao, and G. Zhou, "Bertrand vs. Cournot competition in distribution channels with upstream collusion," International Journal of Production Economics, vol. 204, pp. 278-289, 2018.

[21] T. Melkonyan, H. Zeitoun, and N. Chater, "Collusion in Bertrand vs. Cournot competition: a virtual bargaining approach," Management Science, vol. 64, no. 12, pp. 5599-5609, 2018.

[22] H. Horn and A. Wolinsky, "Bilateral monopolies and incentives for merger," The RAND Journal of Economics, vol. 19, no. 3, pp. 408-419, 1988.

[23] S. S. Askar, "On Cournot-Bertrand competition with differentiated products," Annals of Operations Research, vol. 223, no. 1, pp. 81-93, 2014.

[24] F. Várdy, "The value of commitment in Stackelberg games with observation costs," Games and Economic Behavior, vol. 49, no. 2, pp. 374-400, 2004.

[25] J. S. Heywood and M. McGinty, "Leading and merging: convex costs, Stackelberg, and the merger paradox," Southern Economic Journal, vol. 74, no. 3, pp. 879-893, 2008.

[26] W. Li and J. Chen, "Backward integration strategy in a retailer Stackelberg supply chain," Omega, vol. 75, pp. 118-130, 2018.

[27] X. Yang, Y. Peng, Y. Xiao, and X. Wu, "Nonlinear dynamics of a duopoly Stackelberg game with marginal costs," Chaos, Solitons \& Fractals, vol. 123, pp. 185-191, 2019.

[28] M. A. Hit, R. D. Ireland, and R. E. Hoskisson, Strategic Management: Competitiveness and Globalization, 2013.

[29] T. Laosirihongthong, K. C. Tan, and V. R. Kannan, "The impact of market focus on operations practices," International Journal of Production Research, vol. 48, no. 20, pp. 5943-5961, 2010.

[30] T. AlGeddawy and H. ElMaraghy, "Assembly systems layout design model for delayed products differentiation," International Journal of Production Research, vol. 48, no. 18, pp. 5281-5305, 2010.

[31] Q. Liu and D. Zhang, "Dynamic pricing competition with strategic customers under vertical product differentiation," Management Science, vol. 59, no. 1, pp. 84-101, 2013.
[32] D. P. Baron, "Vertical differentiation, product innovation, and dynamic competition," Journal of Economics and Management Strategy, vol. 29, no. 3, pp. 635-662, 2020.

[33] P. Mandal and T. Jain, "Partial outsourcing from a rival: quality decision under product differentiation and information asymmetry," European Journal of Operational Research, vol. 292, no. 3, pp. 886-908, 2021.

[34] R. Sousa and G. J. C. da Silveira, "Advanced services and differentiation advantage: an empirical investigation," International Journal of Operations \& Production Management, vol. 40, no. 9, pp. 1561-1587, 2020.

[35] R. K. Tyagi, "On the effects of downstream entry," Management Science, vol. 45, no. 1, pp. 59-73, 1999.

[36] Y. He and X. Zhao, "Coordination in multi-echelon supply chain under supply and demand uncertainty," International Journal of Production Economics, vol. 139, no. 1, pp. 106-115, 2012.

[37] G. J. Kyparisis and C. Koulamas, "Competition in two-tier serial and assembly supply chains with general consumer utility functions," International Journal of Production Research, vol. 56, no. 17, pp. 5854-5865, 2018.

[38] F. Bloch, "Endogenous structures of association in oligopolies," The RAND Journal of Economics, vol. 26, no. 3, pp. 537-556, 1995.

[39] S.-H. Cho and X. Wang, "Newsvendor mergers," Management Science, vol. 63, no. 2, pp. 298-316, 2017.

[40] Z. Yuan, F. Y. Chen, X. Yan, and Y. Yu, "Operational implications of yield uncertainty in mergers and acquisitions," International Journal of Production Economics, vol. 219, pp. 248-258, 2020. 